\title{
Analisis Video Comments To Followers Ratio Instagram Pada 5 Brand Asli Indonesia Yang Sudah Mendunia
}

\author{
Ni Komang Arista Sriastiti \\ STIMIK STIKOM Indonesia \\ $\underline{\text { Aristasriastiti14@gmail.com }}$
}

\begin{abstract}
Instagram is a photo and video-based social media that was launched on October 6, 2010, after being released in a day Instagram got 25.00 users, and in the next ten years, the number of users increased to more than one billion. Instagram is a social media application that provides a fast and fun way to share media through platform-specific content, namely snap photos, choose filters to change the look and feel of photos, and can add comments to posts on the photo. With a very wide user base, Instagram has become one of the platforms for media marketing for business people. For example, 5 Original Indonesian Brands are Worldwide, including: Indomie, Polytron, La Fonte, Tolak Angin, Eiger who use Instagram as a promotional medium. The purpose of this study is to calculate the credibility of the Instagram account performance of 5 Original Indonesian Brands that are Worldwide. The method used in this study is a quantitative exploratory method. The results obtained from this study determine that Polyton's Instagram account has a high credibility value so that it ranks first out of 5 Worldwide Original Indonesian Brands and has good account performance.
\end{abstract}

\begin{abstract}
ABSTRAK
Instagram merupakan media social berbasis foto dan video yang diluncurkan pada 6 Oktober 2010, setelah dirilis dalam sehari Instagram mendapatkan 25.00 pengguna, dan dalam sepuluh tahun kemudian, jumlah pengguna meningkan menjadi lebih dari satu miliar. Instagram adalah sebuah aplikasi media sosial yang memberikan cara cepat dan menyenangkan untuk berbagi media melalui konten platform tertentu, yaitu snap foto, memilih filter-filter untuk mengubah tampilan dan nuansa foto, serta dapat menambahkan komentar dalam posting foto tersebut. Dengan pengguna yang sangat luas membuat Instagram menjadi salah satu platform untuk media marketing bagi para pelaku usaha. Contohnya adapun 5 Brand Asli Indonesia yang Mendunia, diantaranya : Indomie, Polytron, La Fonte, Tolak Angin, Eiger yang menggunakan Instagram sebagai media promosi. Adapun tujuan dari penelitian ini untuk menghitung kredbilitas performa akun Instagram 5 Brand Asli Indonesia yang Mendunia. Metode yang digunakan dalam penelitian ini yaitu metode eksploratif kuantitatif. Hasil yang diproleh dari penelitian ini menentukan bahwa akun Instagram Polyton memiliki nilai kerdibilitas yang tinggi sehingga menempati pringkat pertama dari 5 Brand Asli Indonesia yang Mendunia dan memiliki performa akun yang baik.
\end{abstract}

Keyword : Instagram ; Media Sosial ; Credibility Account Instagram ; Video Comments to Followers ; 5 Brand Asli Indonesia yang Mendunia. 


\section{PENDAHULUAN}

Dalam beberapa tahun terakhir, penggabungan berbagai jenis teknologi telah meningkatkan jumlah pilihan yang dimiliki orang dan lembaga untuk melakukan kontak dan tetap berhubungan. Dengan perkembangan teknologi informasi dan komunikasi yang pesat sehingga manusia memiliki dunia informasi, hiburan, dan pilihan komunikasi, semua di ujung jari mereka. Tidak sulit untuk memahami seruan tersebut. Selain panggilan suara dan video, pengguna ponsel memiliki akses instan ke email, media social dll. Semua ini didukung oleh ekosistem aplikasi seluler dan sumber daya online yang luas dan terus berkembang. Media sosial adalah media daring yang digunakan untuk kebutuhan komunikasi jarak jauh, proses interaksi antara user satu dengan user lain, serta mendapatkan sebuah informasi melalui perangkat aplikasi khusus menggunakan jaringan internet. Tujuan dari adanya social media sendiri adalah sebagai sarana komunikasi untuk menghubungkan antar pengguna dengan cakupan wilayah yang sangat luas.

Perkembangan dari social media tentunya dapat dirasakan oleh banyak pengguna internet di seluruh penjuru dunia. Dengan banyaknya jejaring media social yang bisa digunakan sebagai alat komunikasi. Salah satu contoh aplikasi media social yang banyak digunakan saat ini yaitu Instagram [1]. Instagram adalah sebuah aplikasi media sosial yang memberikan cara cepat dan menyenangkan untuk berbagi media melalui konten platform tertentu, yaitu snap foto, memilih filter-filter untuk mengubah tampilan dan nuansa foto, serta dapat menambahkan komentar dalam posting foto tersebut [2].

Menurut laporan hasil survei We are Social (2018) dan Laporan survei APJII (2018), instagram menempati urutan ke-2 sebagai platform media sosial pengguna terbanyak saat ini [3]. Saat ini Instagram bukan hanya sebagai sarana komunikasi dan informasi saja, melainkan sudah mewabah kebeberapa sektor terutama pemasaran. Salah satu pemasaran yang kerap terjadi di Instagram adalah penjualan, periklanan, branding, dan pelayanan jasa. Dilihat dari banyaknya pengguna Instagram di dunia maka banyak brand memanfaatkan peluang tersebut, tidak terkecuali brandbrand dari Indonesia. Contohnya adapun 5 Brand Asli Indonesia yang Mendunia, diantaranya : Indomie, Polytron, La Fonte, Tolak Angin, Eiger .

Penelitian ini menggunakan metode kuantitatif dan menggunakan rasio-rasio yang ada pada Instagram yang digunakan sebagai alat ukur dalam menilai beragam aspek yang ada pada Instagram. Beberapa aspek yang dapat dinilai menggunakan rasio - rasio hasil dari penelitian tersebut yaitu, yang pertama ingetsmen yang ada pada akun Instagram tersebut, apakah ingetsmen 
dari akun tersebut sudah bagus atau belum. Kedua, rasio - rasio ini juga bisa digunakan untuk mengukur kredibilitas dari akun Instagram tersebut. Dan yang ketiga, untuk menilai performa dari konten atau post yang posting pada akun Instagram tersebut. [4]

\section{TINJAUAN PUSTAKA}

Semakin berkembangnya teknologi informasi mengakibatkan penyebaran informasi menjadi semakin berkembang, salah satunya dengan munculnya media baru. Sebagian besar aktivitas kehidupan masyarakat tidak dapat dipisahkan dengan internet [5]. Media Sosial adalah konten online yang dibuat menggunakan teknologi penerbitan yang sangat mudah diakses dan terukur. Hal yang paling penting dari teknologi ini adalah terjadinya pergeseran cara mengetahui orang, membaca dan membagi berita, serta mencari informasi dan konten [6].

Media sosial yang sedang banyak diminati oleh khalayak saat ini adalah Instagram. Melalui media sosial Instagram, masyarakat khususnya remaja tidak segan untuk mengunggah segala macam kegiatan, keluh kesah, foto pribadi dan video singkat untuk disampaikan kepada masyarakat luas melalui akun media sosial Instagram dalam membentuk identitas diri mereka [7].

Instagram dikembangkan oleh Kevin Systrom dan dirilis pada tahun 2010. Media sosial ini awalnya merupakan aplikasi fotografi, karena popularitasnya semakin meningkat fiturfitur baru pun banyak ditambahkan seperti hashtag, photo filter, dukungan untuk foto resolusi tinggi, stories, live streaming dan lainya. Dengan banyaknya fitur pendukung pada Instagram, komunikasi dan pencarian informasi pengguna pun dapat semakin mudah [8].

\section{METODE PENELITIAN}

Untuk mengetahui kredibilitas dari performa akun Instagram 5 Brand Asli Indonesia yang Mendunia, dalam penelitian ini metode yang digunakan adalah metode eksploratif kuantitatif. Penelitian dengan tipe eksploratif ini akan meneliti seluruh katagori pengguna instagram dengan tujuan untuk memperdalam pengetahuan dan mencari ide-ide baru mengenai suatu gejala tertentu, menggambarkan fenomena sosial, dan menjelaskan bagaimana terjadinya suatu fenomena social [9].

Tujuan dilakukannya penelitian ini yaitu untuk mengetahui nilai kredibilitas dari performa akun Instagram 5 Brand Asli Indonesia yang Mendunia, untuk menentukan peringkat pada akun Instagram Brand Asli Indonesia yang Mendunia, adapun beberapa langkah yang perlu dikaukan, dantaranya yaitu : 


\section{Mengeksplorasi Objek Yang Akan Dianalisi}

Dilakukan eksplorasi pada beberapa halaman website yang menyediakan informasi mengenai objek. Setelah eksplorasi ditentukan objek yang akan di teliti, yaitu 5 Brand Asli Indonesia yang Mendunia. Setalah menentukan objek dilakukan pencarian akun-akun Instagram setiap objek.

\section{Menghitung Nilai Rata-Rata Variable Pada Setiap Akun Instagram 5 Brand Asli} Indonesia Yang Mendunia

Pada langkah ini, menghitung nilai variable video comments dan variable followers. Variabel adalah sesuatu yang memiliki nilai bervariasi dimana nilai tersebut dapat dijadikan dasar untuk 4 data yang berbeda seperti rasio, skala, ordinal, nominal dan internal [10] . Untuk menghitung nilai rata-rata dari variabel video comments dan variabel followers yaitu dengan cara mengambil minimal 10 postingan kemudian di hitung sehingga menemukan nilai rata-rata dari masing-masing variabel.

\section{Menghitung Niali Kredibilitas Rasio}

Untuk menghitung nilai kredibilitas dari video comments to followers ratio, peneliti menggunakan cara membagi nilai variabel pertama dengan nilai variabel kedua. Jika video comments memiliki nilai 100 dan Followers memiliki nilai 400, maka cara menghitungnya yaitu $100: 400=0,4$. Dengan begitu nilai dari video comments to followers ratio adalah 0,4 .

\section{Menentukan Peringkat Pada akun Instagram 5 Brand Asli Indonesia Yang Mendunia}

Untuk penentuan peringkat perlu melihat karakteristik dari rasio yang di teliti. Jika karakteristik rasio merupakan rendah, maka objek yang memiliki nilai terendah akan mendapatkan angka 5 dan objek yang memiliki nilai tertinggi akan mendapatkan angka 1. Namun jika rasio memiliki karakteritik tinggi maka objek yang mendapatkan nilai tinggi akan mendapatkan angka 5 dan objek yang mendapatkan nilai terendah akan mendapatkan angka 1. Setelah mendapatkan hasil kredibilitas ratio maka dapat disimpulkan objek yang mana mendapatkan peringkat 1 sampai dengan peringkat 5 . 


\section{HASIL DAN PEMBAHASAN}

Akun Instagram dari 5 Brand Asli Indonesia yang sudah mendunia diantaranya :

1. Indomie

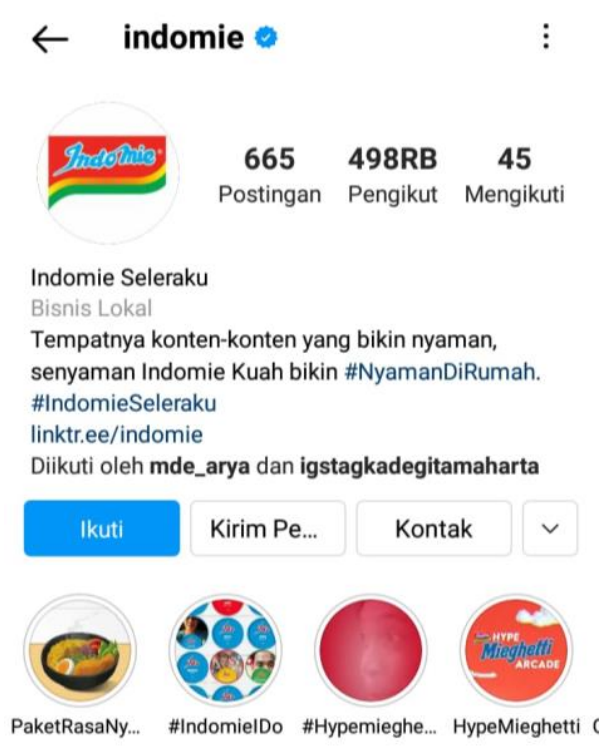

Gambar 1. Akun Instagram Indomie

Sumber :

https://instagram.com/indomie?utm_medium=copy_link

(akses pada 19-10-2021)

2. Polytron

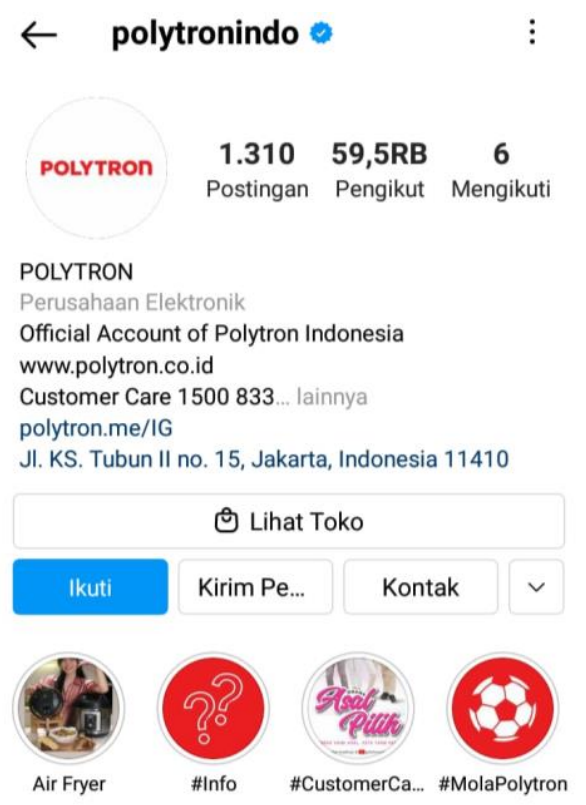

Gambar 2. Akun Instagram Polytron

Sumber :

https://instagram.com/polytronindo?utm_medium=copy_link

(akses pada 19-10-2021) 
3. La Fonte

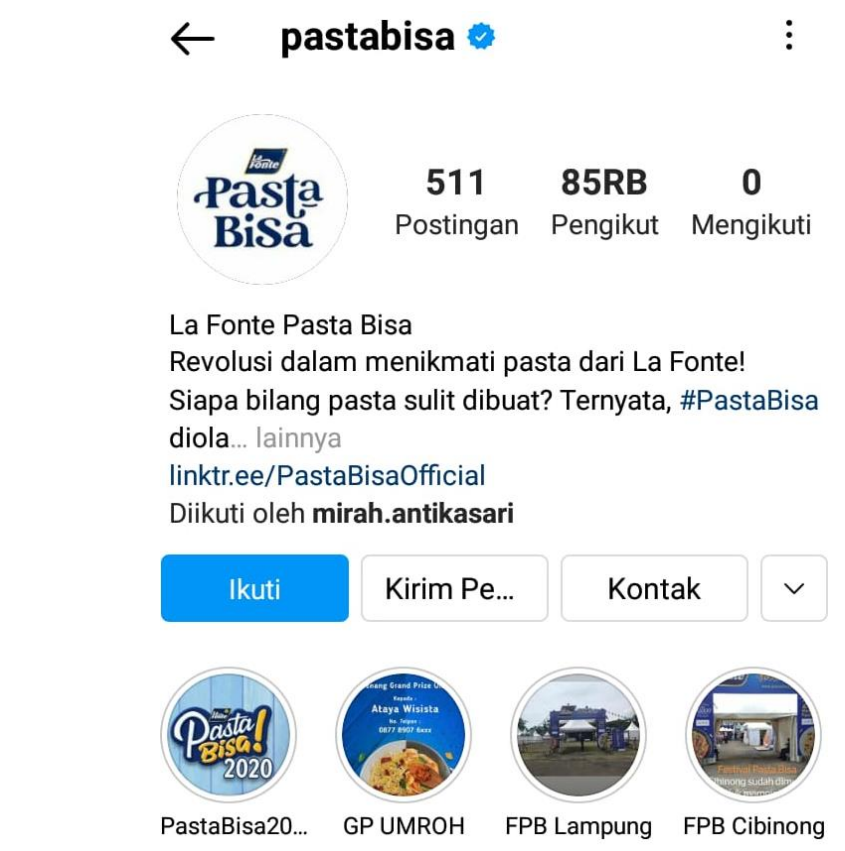

Gambar 3. Akun Instagram La Fonte

Sumber :

https://instagram.com/pastabisa?utm_medium=copy_link

(akses pada 19-10-2021)

4. Tolak Angin
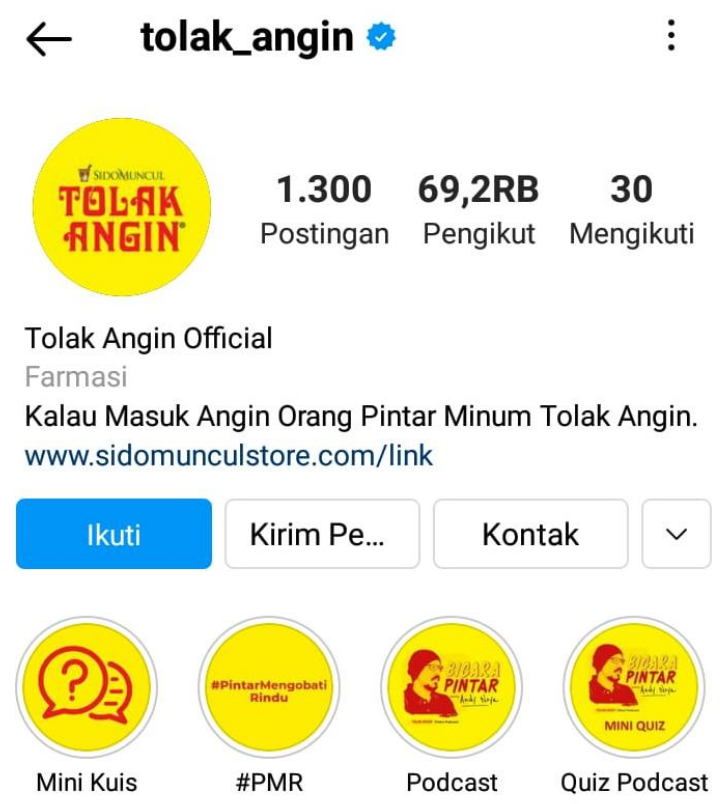

Gambar 4. Akun Instagram Tolak Angin

Sumber :

https://instagram.com/tolak_angin?utm_medium=copy_link

(akses pada 19-10-2021) 
5. Eiger

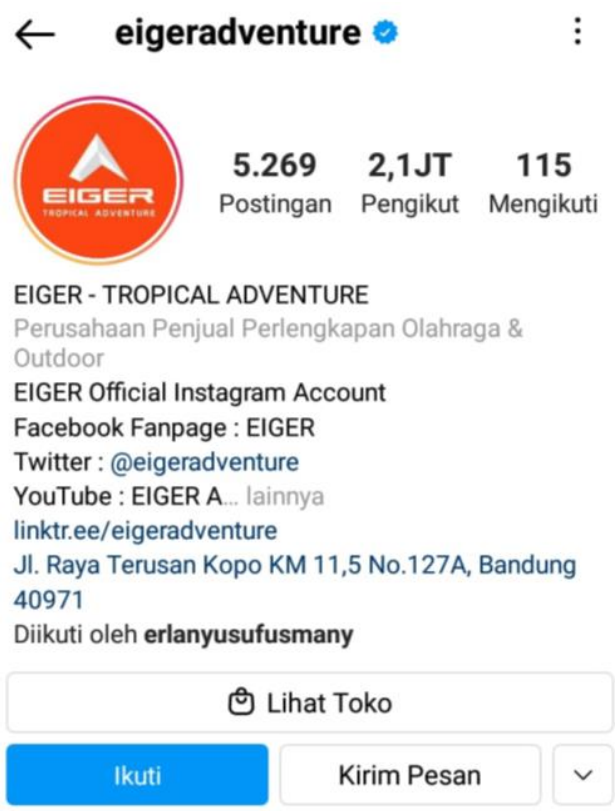

Gambar 5. Akun Instagram Eiger

Sumber :

https://instagram.com/eigeradventure?utm_medium=copy_link

(akses pada 19-10-2021)

Dari kelima akun Instaram Brand Asli Indonesia yang sudah mendunia, peneltian ini bertujuan untuk menentukan nilai dari masing-masing variable yang ada, untuk menghitung rasio Video Comments to Followers dari setiap akun. Pada akun instagram terdapat 7 variabel, diantaranya yaitu :

1. Likes

2. Followers

3. Following

4. Video Likes

5. Video Comments

6. Video Share

7. Video Views

Dari ketujuh variabel tersebut peneliti hanya fokus untuk menemukan hasil dari 2 variabel, yaitu :

1. Video Comments

2. Followers 
Dari kedua variabel tersebut kemudian dianalisa sehingga menemukan nilai rata-rata dari variabel video comments dan variabel followers. Untuk menghitung nilai rata-rata dari kedua variabel tersebut yaitu dengan cara mengambil minimal 10 postingan video kemudian di hitung sehingga menemukan nilai rata-rata dari masing-masing variabel. Berikut merupakan tabel nilai rata-rata dari setiap akun Instaram 5 Brand Asli Indonesia yang sudah mendunia, yaitu :

Tabel 1. Analisa Nilai Rata-Rata Nilai Variable Video Comments dan Followers Akun Instagram Indomie

\begin{tabular}{|c|c|c|}
\multicolumn{3}{|c}{ Indomie } \\
\hline No. & $\begin{array}{c}\text { Video } \\
\text { Comments }\end{array}$ & $\begin{array}{c}\text { Followers } \\
\text { Ratio }\end{array}$ \\
\hline 1 & 452 & 487,000 \\
\hline 2 & 186 & 487,000 \\
\hline 3 & 119 & 487,000 \\
\hline 4 & 152 & 487,000 \\
\hline 5 & 103 & 487,000 \\
\hline 6 & 152 & 487,000 \\
\hline 7 & 198 & 487,000 \\
\hline 8 & 64 & 487,000 \\
\hline 9 & 38 & 487,000 \\
\hline 10 & 40 & 487,000 \\
\hline Total & $\mathbf{1 5 0 . 4}$ & $\mathbf{4 8 7 , 0 0 0}$ \\
\hline
\end{tabular}

Sumber : Pengolahan Data Excel

Tabel 2. Analisa Nilai Rata-Rata Nilai Variable Video Comments dan Followers Akun Instagram Polytron

Polytron

\begin{tabular}{|c|c|c|}
\hline No. & $\begin{array}{c}\text { Video } \\
\text { Comments }\end{array}$ & $\begin{array}{c}\text { Followers } \\
\text { Ratio }\end{array}$ \\
\hline 1 & 1300 & 594,000 \\
\hline 2 & 49 & 594,000 \\
\hline 3 & 35 & 594,000 \\
\hline 4 & 225 & 594,000 \\
\hline 5 & 30 & 594,000 \\
\hline 6 & 136 & 594,000 \\
\hline 7 & 35 & 594,000 \\
\hline 8 & 48 & 594,000 \\
\hline 9 & 85 & 594,000 \\
\hline 10 & 23 & 594,000 \\
\hline Total & $\mathbf{1 9 6 . 6}$ & $\mathbf{5 9 4 , 0 0 0}$ \\
\hline
\end{tabular}

Sumber : Pengolahan Data Excel 
Tabel 3. Analisa Nilai Rata-Rata Nilai Variable Video Comments dan Followers Akun Instagram La Fonte

\begin{tabular}{|c|c|c|}
\multicolumn{3}{|c}{ La Fonte } \\
\hline No. & $\begin{array}{c}\text { Video } \\
\text { Comments }\end{array}$ & $\begin{array}{c}\text { Followers } \\
\text { Ratio }\end{array}$ \\
\hline 1 & 83 & 846,000 \\
\hline 2 & 188 & 846,000 \\
\hline 3 & 41 & 846,000 \\
\hline 4 & 39 & 846,000 \\
\hline 5 & 37 & 846,000 \\
\hline 6 & 64 & 846,000 \\
\hline 7 & 73 & 846,000 \\
\hline 8 & 62 & 846,000 \\
\hline 9 & 79 & 846,000 \\
\hline 10 & 75 & 846,000 \\
\hline Total & $\mathbf{7 4 . 1}$ & $\mathbf{8 4 6 , 0 0 0}$ \\
\hline
\end{tabular}

Sumber : Pengolahan Data Excel

Tabel 4. Analisa Nilai Rata-Rata Nilai Variable Video Comments dan Followers Akun Instagram Tolak Angin

\section{Tolak Angin}

\begin{tabular}{|c|c|c|}
\hline No. & $\begin{array}{c}\text { Video } \\
\text { Comments }\end{array}$ & $\begin{array}{c}\text { Followers } \\
\text { Ratio }\end{array}$ \\
\hline 1 & 10 & 689,000 \\
\hline 2 & 44 & 689,000 \\
\hline 3 & 1 & 689,000 \\
\hline 4 & 4 & 689,000 \\
\hline 5 & 6 & 689,000 \\
\hline 6 & 6 & 689,000 \\
\hline 7 & 7 & 689,000 \\
\hline 8 & 10 & 689,000 \\
\hline 9 & 19 & 689,000 \\
\hline 10 & 77 & 689,000 \\
\hline Total & $\mathbf{1 8 . 4}$ & $\mathbf{6 8 9 , 0 0 0}$ \\
\hline
\end{tabular}

Sumber : Pengolahan Data Excel 
Tabel 5. Analisa Nilai Rata-Rata Nilai Variable Video Comments dan Followers Akun Instagram Eiger

\begin{tabular}{|c|c|c|}
\multicolumn{3}{|c}{ Eiger } \\
\hline No. & $\begin{array}{c}\text { Video } \\
\text { Comments }\end{array}$ & $\begin{array}{c}\text { Followers } \\
\text { Ratio }\end{array}$ \\
\hline 1 & 56 & $2,100,000$ \\
\hline 2 & 102 & $2,100,000$ \\
\hline 3 & 10 & $2,100,000$ \\
\hline 4 & 20 & $2,100,000$ \\
\hline 5 & 11 & $2,100,000$ \\
\hline 6 & 18 & $2,100,000$ \\
\hline 7 & 38 & $2,100,000$ \\
\hline 8 & 19 & $2,100,000$ \\
\hline 9 & 4 & $2,100,000$ \\
\hline 10 & 7 & $2,100,000$ \\
\hline Total & $\mathbf{2 8 . 5}$ & $\mathbf{2 , 1 0 0 , 0 0 0}$ \\
\hline
\end{tabular}

Sumber : Pengolahan Data Excel

Setelah menghitung nilai rata-rata, tahap selanjutnya menentukan hasil akhir nilai rata-rata dari variabel video comments dan Followers, dapat dilihat pada tabel 6 berikut;

Tabel 6. Nilai Variabel Pada Akun Instargam 5 Brand Asli Indonesia yang sudah mendunia

\begin{tabular}{|c|c|c|c|c|c|}
\hline Variable & Indomie & Polytron & La Fonte & $\begin{array}{c}\text { Tolak } \\
\text { Angin }\end{array}$ & Eiger \\
\hline $\begin{array}{c}\text { Video } \\
\text { Comments }\end{array}$ & 150.4 & 196.6 & 16.2 & 14.5 & 28.5 \\
\hline Followers & 487,000 & 594,000 & 846,000 & 689,000 & $2,100,000$ \\
\hline
\end{tabular}

Sumber : Pengolahan Data Excel

Pada akun Instagram terdapat 17 rasio yang relevan digunakan untuk mengukur kredibilitas pada masing-masing akun. Namun pada penelitian ini hanya berfokus untuk menghitung Video Comments to Followers Ratio. Untuk menghitung kredibilitas dari masing-masing akun Instagram setiap Brand, peneliti menghitung dengan cara variabel 1 akan dibagi dengan variabel 2, sehingga ditemukan hasil analisisa dari rasio tersebut. Seperti pada table 7 berikut ini ; 
Tabel 7. Hasil Perhitungan Rasio Akun Instagram

\begin{tabular}{|c|c|c|c|c|c|}
\hline Ratio & Indomie & Polytron & La Fonte & $\begin{array}{c}\text { Tolak } \\
\text { Angin }\end{array}$ & Eiger \\
\hline $\begin{array}{c}\text { Video } \\
\text { Comments } \\
\text { to } \\
\begin{array}{c}\text { Followers } \\
\text { Ratio }\end{array}\end{array}$ & 0.00030883 & 0.000330976 & 0.00001915 & 0.00002104 & 0.00001357 \\
\hline
\end{tabular}

Sumber : Pengolahan Data Excel

Video Comments to Followers Ratio memiliki karakteristik yang tinggi, artinya semakin tinggi nilai yang dihasilkan maka semakin baik kredibilitas dari performa akun tersebut. Untuk memberikan peringkat pada masing-masing Brand, peneliti memberikan angka 5 kepada brand yang mendapatkan nilai tertinggi dan angka 1 untuk brand yang mendapatkan nilai terendah. Berikut merupakan tabel urutan nilai yang dihasilkan oleh masing-masing Brand.

Tabel 8. Nilai Rasio Akun Instargam 5 Brand Asli Indonesia yang sudah mendunia

\begin{tabular}{|c|c|c|c|c|c|}
\hline RATIO & \multicolumn{5}{|c|}{ NILAI } \\
\hline $\begin{array}{c}\text { Video } \\
\text { Comments } \\
\text { to } \\
\text { Followers }\end{array}$ & Indomie & Polytron & La Fonte & $\begin{array}{c}\text { Tolak } \\
\text { Angin }\end{array}$ & Eiger \\
\cline { 2 - 6 } & 4 & 5 & 2 & 3 & 1 \\
\hline
\end{tabular}

Sumber : Pengolahan Data Excel

Dari Tabel Nilai Rasio Akun Instagram 5 Brand Asli Indonesia yang sudah mendunia dapat simpulkan bahwa Polytron mendapatkan nilai tertinggi untuk ratio Video Comments to Followers. Sedangkan Eiger mendapatkan nilai terendah untuk ratio Video Comments to Followers. Maka pada penelitian ini akun Instagram Polytron memiliki kredibilitas performa yang lebih baik dibandingkan dengan akun Instagram yang lainnya. 


\section{KESIMPULAN}

Penitilian ini bertujuan untuk mengetahui kredibilitas performa dari akun Instaram 5 Brand Asli Indonesia yang sudah mendunia menggunakan Video Comments to Followers Rasio. Adapun 5 Brand Asli Indonesia yang sudah mendunia diantaranya Indomie, Polytron, La Fonte, Tolak Angin dan Eiger. Setelah menghitung nilai variable dari kelima akun Instagram Brand Asli Indonesia yang sudah mendunia, dapat disimpulkan bahawa,

- Peringkat pertama adalah akun Instagram Polytron dengan nilai 0.000330976

- Peringkat kedua adalah akun Instagram Indomie dengan nilai 0.00030883

- Peringkat kedua adalah akun Instagram Tolak Angin dengan nilai 0.00002104

- Peringkat kedua adalah akun Instagram La Fonte dengan nilai 0.00001915

- Peringkat kedua adalah akun Instagram Eiger dengan nilai 0.00001357 


\section{DAFTAR PUSTAKA}

[1] Prihatiningsih, Witanti. 2017a. "MOTIF PENGGUNAAN MEDIA SOSIAL INSTAGRAM DI KALANGAN REMAJA.” Jurnal Communication VIII, Nomor. Vol. 1. http://techno.okezone.com/read/2016/0.

[2] Arianti, Gusmia. 2017. "KEPUASAN REMAJA TERHADAP PENGGUNAAN MEDIA SOSIAL INSTRAGRAM DAN PATH.” WACANA, Jurnal Ilmiah Ilmu Komunikasi 16 (2). https://doi.org/10.32509/wacana.v16i2.21.

[3] Saputra, Andi. 2019. "SURVEI PENGGUNAAN MEDIA SOSIAL DI KALANGAN MAHASISWA KOTA PADANG MENGGUNAKAN TEORI USES AND GRATIFICATIONS.” BACA: JURNAL DOKUMENTASI DAN INFORMASI 40 (2): 207. https://doi.org/10.14203/j.baca.v40i2.476.

[4] Putu, I, and Hendika Permana. 2021. "Analisis Rasio Pada Instagram Untuk Penelitian Kualitatif Menggunakan Metode Ekploratif." Jurnal Sistem Informasi Dan Komputer Terapan Indonesia (JSIKTI) 3 (3): 44-56. https://doi.org/10.22146/jsikti.

[5] Arianti, Gusmia. 2017. "KEPUASAN REMAJA TERHADAP PENGGUNAAN MEDIA SOSIAL INSTRAGRAM DAN PATH.” WACANA, Jurnal Ilmiah Ilmu Komunikasi 16 (2). https://doi.org/10.32509/wacana.v16i2.21.

[6] Prihatiningsih, Witanti. 2017a. "MOTIF PENGGUNAAN MEDIA SOSIAL INSTAGRAM DI KALANGAN REMAJA.” Jurnal Communication VIII, Nomor. Vol. 1. http://techno.okezone.com/read/2016/0.

[7] Cahya Sakti, Bulan, and Much Yulianto Jurusan Ilmu Komunikasi. n.d. "PENGGUNAAN MEDIA SOSIAL INSTAGRAM DALAM PEMBENTUKAN IDENTITAS DIRI REMAJA.” http://www.fisip.undip.ac.id.

[8] Suharso, Putut.Muntiah,Ayu. 2020. "PEMANFAATAN MEDIA SOSIAL INSTAGRAM PADA PERPUSTAKAAN PERGURUAN TINGGI.” Edulib 10 (1): 1-14. https://doi.org/10.17509/edulib.v10i1.20984.

[9] Putu, I, and Hendika Permana. 2021. "Analisis Rasio Pada Instagram Untuk Penelitian Kualitatif Menggunakan Metode Ekploratif." Jurnal Sistem Informasi Dan Komputer Terapan Indonesia (JSIKTI) 3 (3): 44-56. https://doi.org/10.22146/jsikti.

[10] Putu, I, and Hendika Permana. 2021. “Analisis Rasio Pada Instagram Untuk Penelitian Kualitatif Menggunakan Metode Ekploratif." Jurnal Sistem Informasi Dan Komputer Terapan Indonesia (JSIKTI) 3 (3): 44-56. https://doi.org/10.22146/jsikti. 